\title{
Primary health care from the global perspective: lessons learned from current research
}

Primary health care was declared the model for global health policy at a 1978 (World Health Organization, 1978) meeting of health ministers and experts from around the world. Primary health care requires a change in socioeconomic status, distribution of resources, a focus on health system development, and emphasis on basic health services (Magnussen et al., 2004). Irrespective of the model of provision, primary care currently faces challenges resulting from a change of demand from the population, a change of the supply of care, and changes in the financial and technological context. Health care systems will need to adapt to the challenges of multimorbidity in ageing populations; the expansion of non-communicable diseases that need to be tackled with new strategies; problems of sustainability and financial constraints and a shrinking workforce (Kringos et al., 2015). Well-organized and strong primary care may play a major role in successfully coping with these challenges, together with empowered patients. When all these challenges are considered, it could be said that primary care is facing high expectations nowadays. It is expected that primary care can help health systems become more responsive to changing health needs, offer more integrated care delivery, and increase the efficiency of the system overall (Kringos et al., 2015).

In order to meet all these expectations, we need more data and evidence to redesign primary care systems in line with these promises from welldesigned and high-quality research studies. There is a lot to learn from individual country experiences and also comparative international studies at global level. Barbara Starfield, whose work had provided early international comparative primary care data, underlined the importance of having an international perspective to understanding some of the important policy-related determinants of health, including those related to the provision of health care services (Starfield and Leiyu, 2002; Starfield, 2011). She declared that, health policies designed to assure equitable distribution of primary care resources will contribute to better health overall.
However, the relative contribution of other health policies, especially those related to facilitation of appropriate use of specialized and technologyoriented care, as well as policies to encourage better primary care/specialty care coordination, remain to be explored (Starfield and Leiyu, 2002). A brief exploration of this kind, a collaborative care model in mental health, can be found in this issue of our journal. The paper by Villamil-Salcedo et al. (2017) describes a three-year experience from Mexico City. In this model, general practitioners collaborated with psychiatrists for diagnosis and treatment of depression and anxiety disorders in primary care centres. Collaborative care allowed general practitioners to be more aware about mental health problems and they were more interested in the identification of these conditions after the collaborative process. I do believe this interesting article will shed a light to others in different countries willing to establish such a collaboration between speciality care and primary care, and what is more it provides inspiration for developing integrated care models.

After the declaration of Alma Ata, two major schools of thought dominated the debate on implementation strategies of primary health care in different health care settings: those supporting "selective" primary health care (SPHC) and those advocating "comprehensive" primary health care (CPHC) (De Maeseneer et al., 2007). The advocates of selective primary health care stated that the large and laudable scope of the Alma Ata Declaration was unattainable due to its prohibitive cost and the numbers of trained personnel required to implement the approach. A more selective approach would attack the most severe public health problems. The advocates of comprehensive primary health care emphasized that the improvement of health care delivery systems is only one aspect of the reforms needed. It incorporates a philosophy of health and health care as a basic human right that, if necessary, also requires the re-shaping of global developmental designs to include community participation in the 
decision making and the implementation of primary health care activities (De Maeseneer et al., 2007). Considered too idealistic and expensive, $\mathrm{CPHC}$ was replaced with a disease-focussed, selective model in many health care settings. After several years of investment in vertical interventions, preventable diseases remain a major challenge for developing countries. However, the selective model has not responded adequately to the interrelationship between health and socioeconomic development, and a rethinking of global health policy becomes an issue that needs urgent attention (Magnussen et al., 2004). A paradigm shift from 'disease-oriented' care to 'goal-oriented' care is needed, and on top of that, patient participation and empowerment, diversity, and the context will be the key issues for achieving CPHC (De Maeseneer et al., 2012). The central attributes of primary care are defined as: first contact (accessibility), longitudinality (person-focussed preventive and curative care overtime), patient-oriented comprehensiveness and coordination (including navigation towards secondary and tertiary care). Besides taking care of the needs of the individuals, primary health care teams are also looking at the community, especially when addressing social determinants of health. The community-oriented primary care (COPC) experience integrates public health focus and primary health care has potential to address the social determinants of health through universal access and through its contribution to empowerment and social cohesion. The multidisciplinary primary care teams and the involvement of the local community is essential for the development of inter-sectorial action for health (De Maeseneer et al., 2007).

In this issue Cronfalk et al. (2017) elaborated feasibility of preventive home visits for older people. They concluded that a structured model of preventive home visits and collaboration between highly specialized health care professionals are important factors for reliable health promoting risk assessments of elderly home dwellers. This study deserves attention as an example of CPHC and also as a study realized in the community. The authors used a multidisciplinary approach, utilising a multi-professional health team for the older people. This team met each week to evaluate risk assessments of the participants and make recommendations to be sent to each respective general practitioner. The results of this study will be useful for planning CHPC strategies in similar settings

Primary Health Care Research \& Development 2017; 18: 209-211 with a community-oriented approach. The study identified approximately $22 \%$ older persons with increased risk for developing illness. Next step will be to test appropriate preventive measures to retain the risk groups from the possible diseases.

Chatterjee et al. (2017) contributed to this issue with a short research report. They opened up the discussion of long-acting benzodiazepine usage among older people. Despite reported unfavourable effects on morbidity and mortality (Sithamparanathan et al., 2012), 3.3\% was the prevalence of benzodiazepine consumption reported by the authors. From the global perspective, polypharmacy and multimorbidity are two major challenges for primary care teams while providing health care to older people. The high prevalence of multimorbidity in the community suggests that single, disease-oriented management programmes may be less effective or efficient tools for high-quality care compared to person-centred approaches (Pefoyo et al., 2015).

The papers included in this issue have potential contributions to our understanding of how primary health care can be strengthened in order to meet changing needs of the populations in 21st century, especially in terms of comprehensiveness, community orientation, and multidisciplinary primary care teams.

Mehmet Akman Associate Editor Associate Professor Department of Family Medicine Marmara University School of Medicine Istanbul, Turkey

\section{References}

Chatterjee, D., Iliffe, S., Kharicha, K., Harari, D., Swift, C., Gillman, G. and Stuck, A.E. 2017: Health risk appraisal in older people 7: long-acting benzodiazepine use in community-dwelling older adults in London: is it related to physical or psychological factors? Primary Health Care Research and Development 18, 253-60.

Cronfalk, B.G., Fjell, A., Carstens, N., Rosseland, L.M.K., Rongve, A., Rönnevik, D.H., Seiger, A., Skaug, K., Vae, K.J.U., Wennersberg, M.H. and Boström, A.M. 2017: Health team for the elderly: a feasibility study for preventive home visits. Primary Health Care Research and Development 18, 242-52.

De Maeseneer, J., Willems, S., De Sutter, A., Van de Geuchte, I. and Billings, M. (editors) 2007. Primary health care as a strategy for achieving equitable care: a literature review. Ottawa: Health Systems Knowledge Network. 
De Maeseneer, J., Roberts, R.G., Demarzo, M., Heath, I., Sewankambo, N., Kidd, M.R., van Weel, C., Egilman, D., Boelen, C. and Willems, S. 2012: Tackling NCDs: a different approach is needed. The Lancet 379, 1860-61.

Kringos, D., Boerma, W.G.W., Hutchinson, A. and Saltman, R.B. (editors) 2015. Building primary care in a changing Europe. Copenhagen: WHO.

Magnussen, L., Ehiri, J. and Jolly, P. 2004: Comprehensive versus selective primary health care: lessons for global health policy. Health Affairs 23, 167-76.

Pefoyo, A.J.K., Bronskill, S.E., Gruneir, A., Calzavara, A., Thavorn, K., Petrosyan, Y., Maxwell, C.J., Bai, Y.Q. and Wodchis, W.P. 2015: The increasing burden and complexity of multimorbidity. BMC Public Health 15, 1-11.
Sithamparanathan, K., Sadera, A. and Leung, L. 2012: Adverse effects of benzodiazepine use in elderly people: a meta-analysis. Asian Journal of Gerontology and Geriatrics 7, 107-1.

Starfield, B. and Leiyu, S. 2002: Policy relevant determinants of health: an international perspective. Health Policy 60, 201-18.

Starfield, B. 2011: Challenges to primary care from co- and multi-morbidity. Primary Health Care Research \& Development 12, 1-2.

Villamil-Salcedo, V., Vargas-Terrez, B.E. and Díaz-Anzaldúa, A. 2017: Collaborative Care model in mental health. Scope and experiences after three years of activity in Mexico City. Primary Health Care Research and Development 18, 227-34.

World Health Organization. 1978: Declaration of Alma-Ata. Retrieved 20 March 2017 from http://www.euro.who.int/_ data/assets/pdf_file/0009/113877/E93944.pdf?ua=1 